FILOLOGIJA 67, Zagreb 2016.

Petar Bašić

UDK 27-282 Kašić, B.'

http://doi.org/10.21857/yvjrdcnnzy

Pregledni članak

Primljen 18.II.2016.

Prihvaćen za tisak 26.IX.2016.

Katolički bogoslovni fakultet

Vlaška 38, HR-10000 Zagreb

petar.basic@kbf.hr

\title{
KAŠIĆEV RITUAL RIMSKI: TRAGOM JEDNE ZABUNE
}

U Kašićevu prijevodu Rituala rimskoga (1640.) dogodila se vrlo neobična zabuna: jedan tekst dvaput je preveden i otisnut na dvjema susljednim stranicama, recto i verso. U prijevodu ima različitih vrsta razlika, $\mathrm{i}$ većih i manjih. Autor ih u ovome svome radu analizira i pokušava izvući neke zaključke.

Rašireno je mišljenje da je Kašić prevodio doslovno, riječ po riječ, tako da se poštuje značenje svake riječi, a po mogućnosti i gramatički oblici. ${ }^{1}$ Toga doista ima, pogotovo u njegovu prijevodu Biblije, gdje je doslovnost bila uobičajena pa i zadana, no kad se njegovo prevođenje cjelovitije razmotri, vidi se da on pokazuje i suprotnih sklonosti, čak jako naglašenih. ${ }^{2}$ Tako u svojem prijevodu Rituala rimskoga Kašić je, premda se radi o liturgijskoj knjizi, pristupio s iznenađujuće mnogo slobode, kako u prevođenju, tako i u uvrštavanju dodataka. ${ }^{3}$

${ }^{1}$ Tako V. Horvat na početku svojega članka Kašićev ispravak Bandulavićeva Lekcionara. »Correttione dell'epistole et evangelii illirici«, Vrela i prinosi 19(1992/1993)217-230.

2 Što se tiče Kašićeva prijevoda Rituala rimskoga, to će se moći lako pratiti jer se uz kritičko izdanje koje je u pripremi kani paralelno objaviti i latinski predložak.

${ }^{3}$ Spomenimo samo tekstove dodane na početku knjige, a koji ne spadaju u Ritual. Odmah nakon naslovnice donosi u prozi posvetu Urbano VIII. Pont. Max. Bartholomeus Cassius Dalmata Felicitatem, gdje opravdava prijevod Rituala na hrvatski (ilirski) jezik i ujedno zagovara objavljivanje svojega Novog zavjeta (selecta a me ex antiquis Illyricis codicibus Versio Illyrica). Slijedi nova posveta papi Urbanu VIII., ovaj put u stihovima. Nakon nove naslovnice, sada na hrvatskome, dolazi generalov nihil obstat i imprimatur magistra papinske palače, a zatim apostolska konstitucija pape Pavla V., prevedena iz latinskog izdanja Rituala. Nakon toga se Kašić obraća »Blagomu i milomu štiocu « i u svojevrsnoj jezičnoj raspravi naširoko obrazlaže svoj naum, no ni ovdje ne propušta pozvati svećenike da potaknu svoje biskupe da od Rima zatraže objavljivanje njegova prijevoda Svetoga pisma. Zatim dolaze kazala kao u latinskom izdanju, a nakon njih opet jedan veliki Kašićev dodatak: PISMO GARGURA PAPE TRINADESTOGA VARH NOVOGA KALENDARA i KALENDAR IZ RIMSKOGA MISALA te SPOVIDAN'JE PRAVE VIRE (str. [XXVII-XXXVI] + 1-82). 
Nakon tih uvodnih napomena vraćamo se temi najavljenoj u naslovu. Kašiću se, u njegovu priređivanju hrvatskog izdanja Rituala rimskoga, dogodilo nešto vrlo neočekivano: jedan te isti tekst preveo je dvaput, $i$ tekst je otisnut na dvjema susljednim stranicama, recto i verso (str. 431 i 432). Ovdje ćemo razmotriti zašto je ta zabuna zanimljiva. Najprije donosim usporedo presliku tih dviju stranica.

\begin{tabular}{|c|}
\hline 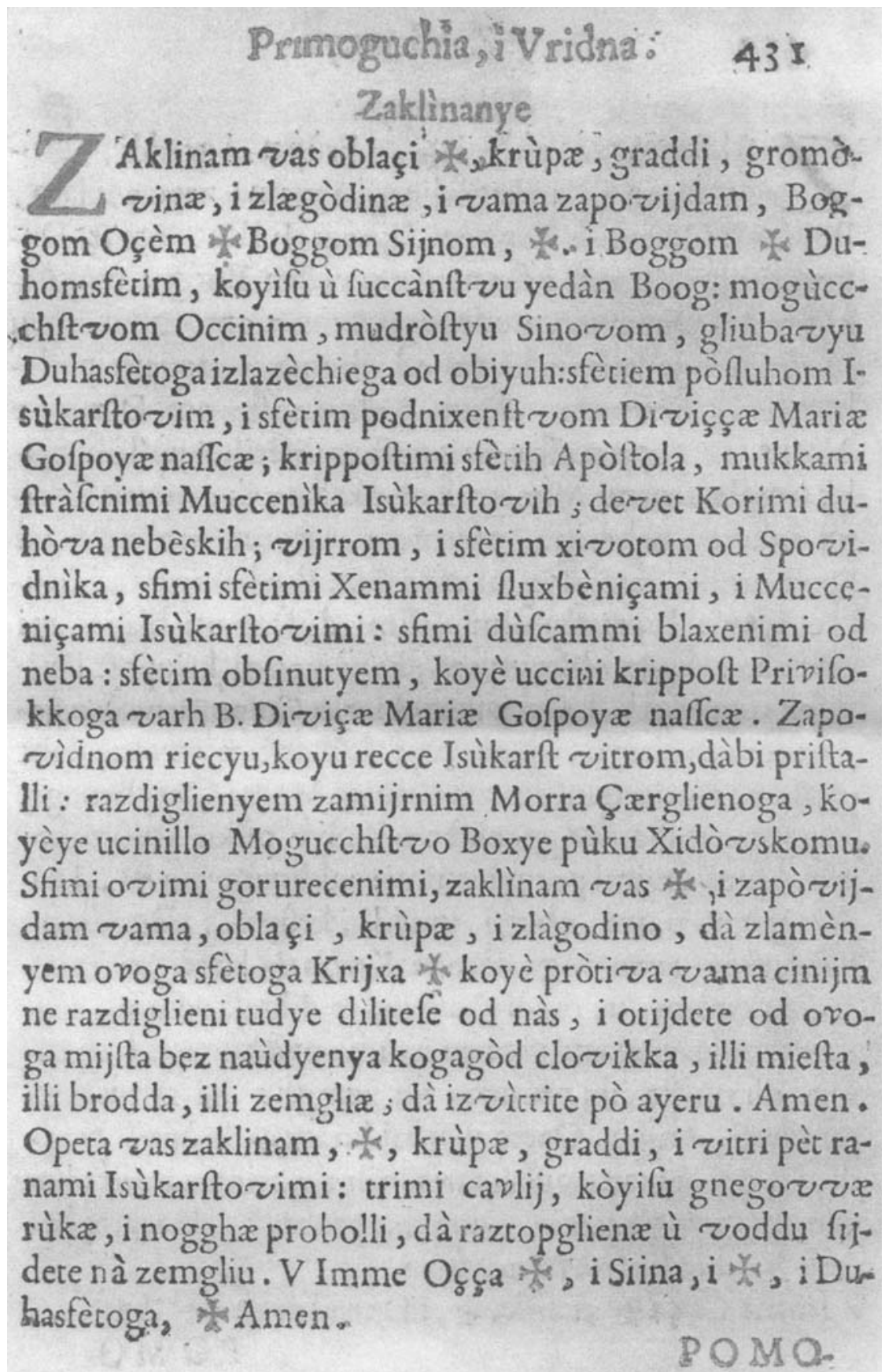 \\
\hline
\end{tabular}




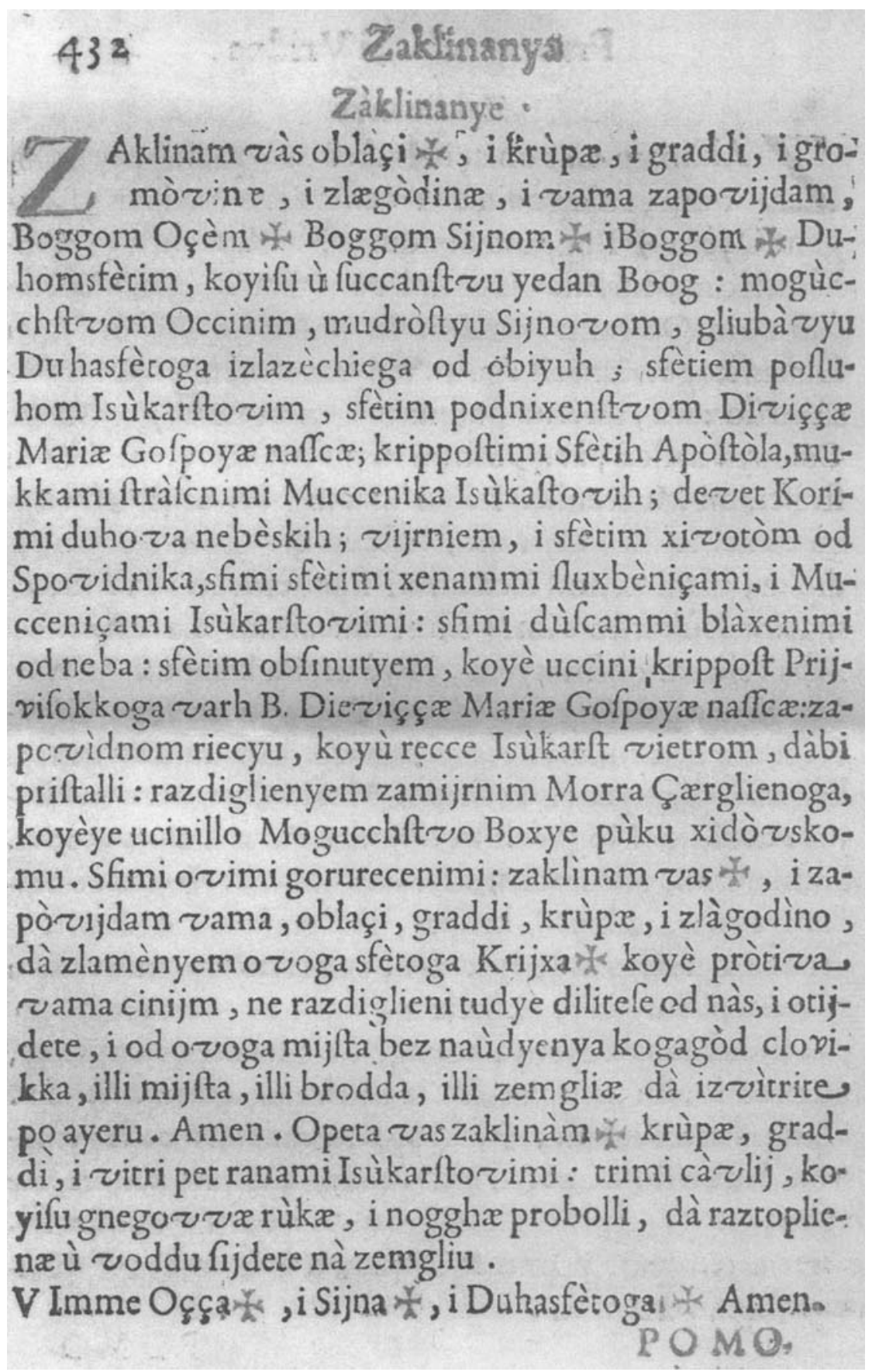


Na preslikama su, kako je rečeno, dva prijevoda istoga latinskog teksta. Najprije ćemo pokušati odgovoriti na pitanje kako se mogla dogoditi zabuna da se jedan tekst prevede i otisne dvaput, a zatim ćemo se pozabaviti razlikama između tih dvaju prijevoda, a njih ima podosta.

Tekst dviju stranica o kojima je ovdje riječ pripada Kašićevu drugom dodatku na kraju knjige (Zaklinan'ja primoguća i vridna..., str. 423-445)4. Taj se dodatak, koliko sam uspio istražiti, u latinskom Ritualu pojavljuje prvi put u 'neslužbenom' ${ }^{5}$ rimskom izdanju iz 1652 ., a zatim u mletačkim izdanjima počevši od 1656. (nema ga u mletačkom izdanju iz 1637.). Naslov latinskog teksta glasi: Coniurationes potentissimæ et efficaces ad expellendas, \& fugandas aereas tempestates... a R. presbytero Petro Locatello tit. S. Cassiani Bergomi collectæ. Vrlo je vjerojatno da Kašić taj tekst nije preuzeo ni iz jednoga latinskog izdanja Rituala (takvo izdanje barem zasad nije mi poznato) ${ }^{6}$, nego izravno iz knjižice koju je P. Locatellus objavio u više navrata: 1604., 1609., 1619., 1626. pod naslovom Coniurationes potentissimæ, et efficaces ad expellendas et fugandas aereas tempestates, a Dæmonibus per se, sive ad nutum cuiusvis diabolici ministri excitatas, ex diversis ... auctoribus collectre, etc. Kasnije je knjižica objavljivana pod neznatno promijenjenim naslovom (Exorcismi potentissimi...). U rukama sam imao izdanja iz 1675. i 1680., iz kojih se jasno vidi da je to isto djelo koje je objavljivano pod naslovom Coniurationes potentissimæ... Kašić je, čini se, bio prvi koji je te tekstove (svoj drugi dodatak) uvrstio u Ritual. Ta knjižica kasnije, dekretom od 4. prosinca 1725., dolazi na popis zabranjenih knjiga, ${ }^{7}$ zbog čega se njezini

${ }^{4}$ Rituale Romanum Urbani VIII. pont. max. iussu editum illyrica lingua, Romae, Ex Typographia Sac. Congreg. de Propag. Fide, M.D.C.XL, Superiorum permissu / Ritual rimski istomačen slovinski po Bartolomeu Kasiću popu bogoslovcu od Družbe Jesusove penitenciru Apostolskomu, u Rimu, iz Utiestenice Svet. Skupa od Razplodjen'ja S. Viere, 1640. (primjerak samostanske knjižnice Sv. Ksaver, Zagreb, sign. I. III br. 30). - Pretisak Rituala objavljen je 1993., priredio Vladimir Horvat.

${ }^{5}$ Pod "službenim" izdanjima podrazumijevam ona što su ih izdali Typographia Reuerendæ Cameræ Apostolicæ (1614., 1615., 1617., 1636.) i Sacra Congr. de Prop. Fide (1658. i 1750.). Druga izdanja bila bi "neslužbena".

${ }^{6}$ Pitanje latinskog predloška Kašićeva Rituala opširno sam obradio u jednom drugom članku (Koji je bio latinski predložak Kašićeva Rituala rimskoga [1640.]?, u: Bogoslovska smotra 84/2014, 4, 787-803). Pregledao sam dvadeset i četiri latinska izdanja i analizirao elemente razlikovanja te ih stavio u odnos s Kašićevim vlastitostima. Mnoge pojedinosti upućuju na to da bi traženi predložak mogao biti neko od mletačkih izdanja između 1620. i 1637., ali ni do jednoga od njih zasad nisam uspio doći.

${ }^{7}$ Djelo je navedeno na svome mjestu po abecednom redu: Lucatellus Petrus. Conjurationes potentissimae, \& efficaces ad expellendas, \& fugandas aereas potestates. Decr. 4. Decembris 1725., u: Index librorum prohibitorum sanctissimi domini nostri Gregorii XVI pontificis maximi jussu editus. Romae MDCCCXLI. Ex Typographia Reverendae Camerae Apostolicae. Cum summi pontificis privilegio. - Postoji određe- 
tekstovi izostavljaju već u mletačkom izdanju iz 1738. (tekstovi su još zadržani u mletačkom izdanju iz 1718.). ${ }^{8}$

Još bismo se mogli upitati nije li možda i u Kašićevu latinskom predlošku dotični tekst bio, zabunom, napisan dvaput. Na tu mogućnost upućuje činjenica da se radi o zaokruženoj cjelini koja ispunjava cijelu stranicu: na vrhu je naslov, a na dnu se najavljuje sljedeći naslov. To bi nas vodilo pretpostavci da su se poklapale stranice latinskog originala, Kašićeva rukopisa i tiskanog Rituala. Kašić naime na obje stranice najavljuje isti naslov koji slijedi: POMO- (=POMOGIIENYA [!] DAVIDOVA). Isto tako valja spomenuti da je dvodijelna živa glava napisana ispravno: na str. 431 ono što dolazi na desnoj (neparnoj), a na str. 432 ono što dolazi na lijevoj (parnoj) stranici.

A sada se okrenimo drugom pitanju, razlikama tih dviju stranica. Najprije donosim popis svih razlika, a zatim ću ih kratko prokomentirati.

Razlike navodim kronološkim redom. Brojke lijevo uz primjere označuju redni broj primjera, a brojke u zagradama označuju red na stranici i jedno i drugo služi za komentar.

str. 431 / str. 432

Zaklìnanye / Zàklinanye vas / vàs

krùpæ / $i$ krùpæ

graddi / $i$ graddi

gromòvine / $i$ gromòvine

5 (3) Sijnom, + . / Sijnom +

jedàn / jedan

mogùccchstvom / mogùcchstvom

Sinovom / Sijnovom

gliubavyu / gliubàvyu

10 (6) obiyuh: / obiyuh;

pòsluhom / posluhom

$i$ sfètim / sfètim

sfètih / Sfètih

Apòstola / Apòstòla

na nedoumica u vezi s prezimenom autora jer se ono susreće $u$ tri oblika: Locatellus, Lucatellus, Lucatellius, no nema ozbiljne sumnje da se ne bi radilo o istom autoru. Spomenuta je i varijanta u naslovu: Exorcismi i Conjurationes, što se provlači i kroz tekst, ali i ta je razlika zanemariva.

${ }^{8}$ Koje li sretne slučajnosti! Od mnogih izdanja koja sam digitalizirana našao na internetu (ukupno 24) ovoga nije bilo, ali je upravo ono, iz razdoblja koje me zanima (1614. - 1750.), jedino koje se nalazi u Hrvatskoj (Knjižnica Bogoslovskog sjemeništa u Zagrebu, br. 15944.). 
$15(9)$

$20(10)$

$25(14)$

$30(19)$

$35(22)$

$40(26)$
Muccenika / Muccenika

Isùkarstovih / Isùkastovih

duhòva / duhova

vijrrom / vijrniem

xivotom / xivotòm

od Spovidnika / od Spovidnika

Xenammi / xenammi

blaxenimi / blàxenimi

Privisokkoga / Prijvisokkoga

Diviçæ / Dieviççæ .

nasscæ. Zapovìdnom / nasscæ: zapovìdnom

$\operatorname{koy} u$ / koy $\ddot{u}$

vitrom / vietrom

Xidòvskomu / xidòvskomu

gorurecenimi, zaklìnam / gorurecenimi: zaklìnam

oblaçi, / oblaçi, graddi

zlàgodino / zlàgodìno

cinijm / cinijm,

dìlitese / dilitese

otijdete od / otijdete, $i$ od

miesta, / mijsta,

zemgliæ ; dà / zemgliæ dà

pò ayeru. / po ayeru.

zaklinam, +, / zaklinàm +

cavlij, kòyisu / càvlij koyisu

raztopglienae / raztoplienae

V Imme / V Imme

i Siina, $i+$, i Du- / i Sijna + , i Du-

\section{Komentar}

Ako bismo pobrojili sve razlike, pa i one najsitnije, bilo bi ih pedesetak. Sve se one mogu razvrstati na više slojeva.

Na prvo mjesto stavili bismo prevodilačke razlike. Na šest mjesta veznik i je donesen ili izostavljen (br. 2-4, 12, 18 i 42); jedna je riječ izostavljena i u br. 30. I razliku u br. 18 (vijrrom / vijrniem) možda možemo svrstati u prevodilačke razlike. Kašić je naime mogao latinsku riječ pročitati jedanput kao fidelem, a drugi put kao fidem. Ali bi se tu moglo raditi i o slagarskoj pogrješci (vidjeti zacrnjena slova).

Jedna je razlika redakcijska: $u$ br. 41 rečenica $\mathrm{V}$ Imme... jedanput je u 
novom odlomku, a jedanput u nastavku. Sasvim je jasno da je Kašić hotimično tako postupio, dok je u latinskom moglo ne biti sasvim jasno gdje je novi odlomak.

Najviše razlika odnosi se na Kašićeva kolebanja. I tu imamo različite vrste razlika: a) refleks jata: Diviçæ / Dieviççæ; vitrom / vietrom; miesta, / mijsta; b) dugi/kratki glas: Sinovom / Sijnovom; Privisokkoga / Prijvisokkoga; c) naglasak: U naglasku je samo jedna prava razlika, i to u samom naslovu: Zaklìnanye / Zàklinanye. Od drugih razlika negdje je naglasak stavljen, a negdje nije; na dva mjesta ima dvostruki naglasak, ali to je očito tiskarska pogrješka (Apòstola / Apòstòla i zlàgodino / zlàgodìno); razlika u udvostručenju suglasnika dolazi samo jedanput (Diviçæ / Dieviççæ); d) pravopisnih razlika je relativno malo: (malo i veliko slovo) sfètih / Sfètih; Xenammi / xenammi; Xidòvskomu / xidòvskomu; (interpunkcijski znakovi) Sijnom, + . / Sijnom +; obiyuh: / obiyuh; nasscæ. Zapovìdnom / nasscæ: zapovìdnom; gorurecenimi, zaklìnam / gorurecenimi: zaklìnam; otijdete od / otijdete, $\boldsymbol{i}$ od; zemgliæ ; dà / zemgliæ dà; zaklinam, + , / zaklinàm +; cavlij, kòyisu / càvlij koyisu

e) ostalo se može svrstati u tiskarske pogrješke: mogùccchstvom / mogùcchstvom; Isùkarstovih / Isùkastovih; raztopglienae / raztoplienae.

Nešto je u svemu ovom ipak znakovito. Kašić gotovo u svim svojim djelima donosi Pomanjkan'ja koja treba ponapraviti, ali ništa od toga s ovih dviju stranica ne navodi u svojim Pomanjkan'jima na kraju Rituala. On redovito donosi samo najvažnija, a druge prepušta čitatelju da ih sam ponapravi. Kad je riječ o pomanjkan'jima u Kašićevu Ritualu, u jednom drugom članku iznio sam tezu da bi ih moglo biti preko 700, sitnijih i krupnijih. ${ }^{9}$ No mislim da iz toga ne bi trebalo nužno zaključiti da je Kašić bio površniji i nemarniji od drugih, nego da je to stvarnost onodobnog tiskarstva, ${ }^{10}$ a istraživači to kao da ne uzimaju dostatno u obzir. Stoga mislim da je ova Kašićeva zabuna višestruko zanimljiva. Ona bjelodano pokazuje kako je

\footnotetext{
${ }^{9}$ Analizirajući dvadeset primjera iz Rituala izabranih po posebnom ključu, zaključno sam ustvrdio: »Od dvadeset navedenih primjera Kašić ispravlja u njih 8. Tako je, u tim primjerima, odnos između ispravljenoga i neispravljenoga 8:12. Opći je dojam da bi takav otprilike mogao biti i odnos između sveukupnih Kašićevih ispravljanja $(49$ [prva paginacija] $+252=301)$ i onoga što nije ispravio. Ako bi bilo tako, onda bi, uz te ispravljene, bilo još preko 400, sitnijih i krupnijih, neispravljenih pogrješaka« (P. BAŠIĆ, O Prvotisku Kašićeva Rituala rimskoga [1640.] i njegovu pretisku [1993.], Filologija 61, 2013, 12; cijeli članak 1-15).

${ }^{10}$ Kašić je to bez imalo okolišanja priznao zapisavši na kraju svojih Pomanjkan'ja: »Evo ti upisah, mili štioče, pomanjkan'ja, kakono imaš ponapraviti ih: ter se nemoj čuditi da ih toliko jest: čudi se da ih nije vele veće budući bili stampaturi utieštenici našega jezika nerazumiteonici: paček zahvali Gospodinu Bogu da se to sve moglo jest i tako utieštiti s velicim mojim trudom« (str. 450).
} 
težak i nesiguran put da se dopre do izvornog autorova teksta. Baca također novo svjetlo i na Kašićev način rada. On je naime podjednako dobro poznavao i latinski i hrvatski jezik, a uz ostale poslove mnogo je prevodio te je zasigurno stekao potrebno iskustvo i rutinu. Nije morao mnogo razmišljati, osim možda kad bi došla koja vrlo rijetka riječ ili izraz. U njegovu prijevodu Svetoga pisma naveo sam mnoge primjere koji to potvrđuju. ${ }^{11}$ Nema ni govora o tome da bi on, kako se pomišljalo, skupljao prethodne prijevode i od njih stvarao novi prijevod.

Kašićev prijevod Rituala ide u doba kada se hrvatski jezik tek počinje pomalo standardizirati pa ne iznenađuju različita kolebanja. O njima rječito svjedoči i ovaj primjer.

\section{Ritual rimski di Bartol Kašić (1640): sulla traccia di un errore}

\section{Riassunto}

Nella sua traduzione croata (1640) del Rituale Romanum (1614) Bartol Kašić ha commesso un interessante errore: ha tradotto due volte lo stesso testo in due pagine successive, recto e verso (p. 431 e 432), ma nella sua traduzione ci sono differenze, piccole e grandi, e l'Autore in questo suo lavoro le analizza e cerca di trarrne rispondenti conclusioni.

Ključne riječi: Bartol Kašić, Ritual rimski (1640.)

Parola chiave: Bartol Kašić, Ritual rimski (1640)

\footnotetext{
${ }^{11}$ Usp. /Biblia Sacra./ Versio Illyrica selecta... Bartholomaei Cassii. Ediderunt Hans Rothe et Christian Hannick. E codicibus manuscriptis transtulerunt Petar Bašić et Julije Derossi et Zlata Derossi. Curis elaboravit atque apparatu critico instruxit Petar Bašić, sv. I, Paderborn... 1999, str. 120, bilj. a i b; str. 223, bilj. a; str. 318, bilj. g; str. 442, bilj. c itd.
} 